\title{
Transición socialista: recepción y desarrollo en el socialismo cubano
}

Jhosman Geriud Barbosa Domínguez

\begin{abstract}
Resumen: La Revolución Cubana llegó al poder en la plenitud de la Guerra Fría, que la instó a la adscripción ineludible a uno de los polos: el capitalismo o el comunismo. Los antecedentes del siglo XIX, las demandas sociales postergadas, la formación marxista por parte de su vanguardia y las tensiones con Estados Unidos la situaron en la dirección del comunismo e inevitablemente en la transición socialista. La recepción e implementación de la experiencia soviética explican la singularidad de su socialismo.
\end{abstract}

Palabras clave: Transición. Recepción. Socialismo cubano. Comunismo. Teoría. Práctica.

\section{The Socialist Transition: Reception and Development in the Cuban Socialism}

\section{Jhosman Geriud Barbosa DOMÍNGUEZ}

Historiador da Universidade Nacional da Colômbia, mestre em Estudos Latinoamericanos (UNAM) e doutor em Economia Política do Desenvolvimento (CEDES/Universidad Autónoma de Puebla).

E-mail:

\begin{abstract}
The Cuban Revolution came to power in the plenitude of the cold War, which urged for a cutting adscription to one of the poles: capitalism or communism. The $19^{\text {th }}$ century backgrounds, the social demands postponed, the Marxist formation on the part of its vanguard and the tensions with the United States, placed it in the direction of communism and inevitably in the socialist transition. The reception and implementation of the Soviet experience, explain the uniqueness of its socialism.
\end{abstract}

Keywords: Transition. Reception. Cuban Socialism. Communism. Theory. Practice. 


\section{Transição socialista: recepção e desenvolvimento no socialismo cubano}

Resumo: A Revolução cubana chegou ao poder durante a Guerra Fria, pedindo o equipamento de corte para um dos pólos: o capitalismo ou comunismo. A história do século XIX, as demandas sociais negligenciadas, a formação marxista da sua vanguarda e as tensões com os Estados Unidos, colocados para o comunismo e, inevitavelmente, na transição socialista. A Recepção e implementação da experiência soviética, explicam a singularidade de seu socialismo.

Palavras-chave: Transição. Recepção. Socialismo cubano. Comunismo. Teoria. Prática.

\section{INTRODUCCIÓN ${ }^{1}$}

Existieron elementos teórico-prácticos anteriores y afines con algunas líneas del socialismo del Este que maduraban en la sociedad cubana de finales del siglo XIX. La adscripción a la vía soviética en abril de 1961 se afincó tanto en elementos de la coyuntura política de la Guerra Fría como estructurales, manifestados también en la génesis del pensamiento cubano.

La teoría marxista, posicionada gracias a su rigor en la interpretación y sistematización del modo de producción capitalista -no sin combates con otras tendencias- así como por su carácter emancipador, ya retumbaba en la Revolución de 1905 y descolló en la indefectible puesta en práctica de sus principios a partir de la Revolución Rusa de Octubre de 1917. Es decir, fue conminada a orientar la transición hacia el comunismo desde la consolidación del socialismo. La dirigencia bolchevique se vio obligada a construir el comunismo sin manual alguno, ya que la teoría marxiana

1 Agradezco las observaciones efectuadas por los evaluadores externos y a la Doctora Anna Popovitch, por su colaboración en la revisión de forma y sintaxis. 
sólo avistó la pervivencia de elementos de la vieja sociedad en la nueva, sin detallar claves para el análisis y las decisiones en la transición socialista. Como diría en su momento Preobrajensky (1968): "Marx ha estudiado en El Capital el capitalismo clásico; nosotros tenemos que estudiar una tentativa, sin duda no muy clásica y quizás aún no clásica en absoluto pero viva, real e históricamente la primera de un sistema concreto de economía socialista-mercantil" (PREOBRAJENSKY, 1968, p. 43).

Dicho debate y prácticas gestadas en el seno de la nueva realidad soviética, junto a la teoría marxista, entregó a la experiencia cubana de los años sesenta un valioso referente. El presente artículo pone en evidencia la centralidad del problema de la transición socialista a partir de la experiencia soviética y la recepción del debate que deviene en el desarrollo del socialismo cubano moderno. Para tal efecto se ofrecen los siguientes ítems: El debate sobre la transición socialista en Rusia; Ideas socialistas cubanas entre siglos; El debate en Cuba; De transición al comunismo hacia el no capitalismo; Nota de cierre.

\section{EL DEBATE SOBRE LA TRANSICIÓN SOCIALISTA EN RUSIA}

Las reflexiones acerca del socialismo y el comunismo se presentan bajo dos formas: en la primera existe la preocupación por su deber ser bajo el signo de la modelación teórica y se exhibe de carácter prospectivo. La segunda forma expresa la tensión teoría-realidad en la práctica cotidiana de la construcción socialista, vía al comunismo. De las dos emanó una literatura que ha estado presente en la Revolución cubana. Sin entrar en detalles, los términos de la primera forma, pueden apreciarse en la crítica que efectúan (MARX; ENGELS, 2011) a los socialismos en su aparte III Literatura socialista comunista, en el Manifiesto Comunista. La controversia giraba en torno a quiénes los promulgan, cómo se comportan tales actores en relación con los principios, y el rigor teórico que evidenciara la posibilidad de realizarlo. Por ende, el fin de la disertación de cada enfoque socialista variaba en su aspiración del tipo de sociedad futura. En el mismo sentido se ha seguido 
construyendo acerca de la utopía socialista hasta las teorizaciones de Heinz Dieterich acerca del socialismo del siglo XXI. ${ }^{2}$

Para el propósito de este trabajo son claves los términos de la segunda forma que se encuentra explícitamente vinculada con el proceso cubano, expresando como se dijo, la tensión teoría realidad, en la construcción del comunismo, desde el socialismo. Es allí, con cimientos en la primera forma, donde se construyeron los elementos y métodos para analizar y desarrollar el socialismo, el cual se concebía como momento intermedio hacia la sociedad comunista o periodo de transición hacia el socialismo mismo pero nunca como un fin en sí mismo.

Marx nunca desarrolló un trabajo sistemático acerca del periodo de transición. Pero en la Crítica al programa de Gotha dejó plasmadas algunas reflexiones al respecto (MARX, 1986). ${ }^{3}$ En tal sentido, en la Rusia de los bolcheviques ${ }^{4}$ se presentó el debate acerca de la transición hacia el comunismo, a partir de la confrontación de la realidad con la teoría marxista. ${ }^{5}$ Entre otros, encontraron los siguientes problemas: ¿Cómo desarrollar la economía en el socialismo, enfrentando la ley del valor? ¿Cómo se organizaba el mercado? ¿A qué velocidad se debían desarrollar las nuevas fuerzas productivas socialistas? ¿Cómo se configuraba el patrón de

2 Dieterich fue asesor y consultor del gobierno de Hugo Chávez, quien dio visibilidad al esfuerzo teórico del sociólogo alemán al nombrar al socialismo en Venezuela como socialismo del siglo XXI.

3 A propósito del programa obrero-alemán propuesto por Lasalle, Marx dice: "De lo que aquí se trata no es de una sociedad comunista que se ha desarrollado sobre su propia base, sino de una que acaba de salir precisamente de la sociedad capitalista y que, por tanto, presenta todavía en todos sus aspectos, en el económico, en el moral y en el intelectual, el sello de la vieja sociedad de cuya entraña procede." (MARX, 1986, p. 16).

4 Marie y Haupt (1972) hacen una precisión respecto a lo que significó ser bolchevique en el periodo pre y revolucionario: los grandes protagonistas, donde figuran Bujarin, Kámenev, Lenin, Stalin, Svérdlov, Trotsky y Zinóviev. El segundo grupo, "La pléyade de Octubre", es más extenso y se divide en cuatro sub grupos.

5 Hobsbawm (2011), en su apartado "La influencia del Marxismo 1880-1914", presenta las tensiones en el seno del naciente marxismo y las otras alternativas tales como el sindicalismo revolucionario, la socialdemocracia, el socialismo no marxista. También recaba en apreciar hasta qué punto eran marxistas los partidos obrero socialistas y el particular atractivo que ocasionaba en los intelectuales. 
acumulación socialista y la división socialista del trabajo? ¿Cuál era la ética dentro del socialismo de cara al consumo? ¿Cómo negocia en términos internacionales un régimen de acumulación socialista con el capitalismo dominante? Los bolcheviques debieron discutir estos asuntos, en el marco de una guerra interna contra el zarismo en declive y los embates de la Primera Guerra Mundial.

En Rusia, según refiere Shanin (1983), se había gestado un sujeto revolucionario - no proletario industrial - campesino agotado por la explotación y la pobreza generada por los kulaks en el contexto de una monarquía zarista atorada en un "desarrollo irregular" (SHANIN, 1983, p. 23). Los hacedores de la Revolución de Octubre tuvieron como antecedente no sólo la visión marxista de la fase revolucionaria sino la lectura que Marx hizo de Nikolai Chernyshevski - y la lectura del propio Chernyshevski (18281889) - a través de las Cartas sin dirección de 1862 dirigidas al Zar Alejandro II y la Crítica de los prejuicios filosóficos contra la propiedad comunal de 1859. Dichos escritos acrecentaron su interés por el proceso ruso, y su estudio le llevó a reformular su postura respecto al proletariado industrial como único sujeto central de la revolución (SHANIN, 1983, p. 127) ${ }^{6}$

Lenin, Trotsky y Stalin conocían la obra de este ruso luchador y fundador del partido "Voluntad del Pueblo" (Narodnaya Volya). Al tomar el poder Stalin, quien fue partidario de una política de enriquecimiento del sector campesino con lenta industrialización (SÁENZ, 2011), giró hacia la industrialización acelerada negando la substancia agrario-campesina de Rusia. Asimismo, ocultó algunos escritos de Marx que daban cuenta de su capacidad de aprendizaje de la realidad acontecida. Las cartas ya aludidas o los borradores preparatorios de sus escritos; particularmente las referidas a las Formaciones económicas precapitalistas, que negaban de cuajo los

6 Marx ya venía descubriendo otros aspectos como la noción de desarrollo desigual. Sus notas de 1882 aglutinan varios puntos que evidencian a un Marx capaz de aprender de la realidad y rebatir su teoría. Tal fue el caso de la "Carta a Vera Zasulich", escondida por los marxistas que consideraron que Marx y Engels habíanse vuelto populistas hacia el final de sus vidas. En dicha carta, Zasulich expresa la importancia de la obra de Marx y le insta a que ofrezca una postura frente al destino de la comuna rusa. 
estadios de evolución lineal, tal cual lo promulgó la nomenclatura estalinista, son algunos ejemplos de esta selectividad respecto a la producción intelectual marxiana.

Lenin (1974) advirtió una incapacidad por parte de los soviets de conducir el mercado y la distribución. Al proponer e implantar por un lapso de seis años (1921 a 1927) la Nueva Política Económica (NEP) cedió el desarrollo de las relaciones de abastecimiento entre los campesinos a una lógica capitalista. Era claro para Lenin que en esa primera fase de aprendizaje de la construcción socialista los Bolcheviques, "aún no sabemos administrar la economía" (LENIN, 1974, p. 9).

Para Preobrajensky (1968) si la crítica de la economía política de Marx había formado su lev motiv en el análisis de la génesis capitalista, ahora, de cara a la construcción del socialismo en el terreno práctico, se requería de una herramienta metodológica diferente (PREOBRAJENSKY, 1968, p. 94). Por tal motivo construyó la categoría "tecnología social" o la "ciencia de la producción socialmente organizada". Asimismo desarrolló la categoría de "Acumulación Originaria Socialista".

Es conocida la engorrosa situación de algunos intelectuales bolcheviques, entre ellos el propio Preobrajensky, por efecto de la intimidación de Stalin y su círculo más cerrado y fiel. Como se aprecia en la obra de (HAUPT, 1972) los cambios de rumbo teórico en Preobrajensky, coadyuvaron al desarrollo de un acalorado debate que luego sería visitado por los revolucionarios cubanos y los intelectuales de la época comprometidos con la Revolución. La obra Nueva economía fue criticada por Bujárin y soslayada de plano y ante el Partido por el mismo Preobrajensky. ${ }^{7}$

El debate central planteado por Lenin giró en torno a la NEP. Había dos preocupaciones centrales: por un lado, la necesidad de omitir, negociar o mantener por un tiempo las relaciones mercantiles capitalistas; es decir el choque entre planificación de la

7 En el XVII Congreso de enero de 1934, dice Preobrajensky: “Mis obras teóricas, incluyendo la nueva economía, han servido de alma para luchar contra el partido..." (HAUPT, 1972, p. 184). 
economía y ley del valor. ${ }^{8}$ Por otro, el imperativo de construir un nuevo tipo de acumulación originaria de tipo socialista que entraba en tensión con la capitalista. Estos dos puntos tenían como ejes de articulación la forma en que se manejaban los excedentes de la producción, la vinculación obrero-campesina a la construcción del comunismo en el socialismo y por ende, el desarrollo de las fuerzas productivas y el nivel de conciencia que ello implicaba. El socialismo en un solo país o la urgencia de la revolución mundial, también eran temas acuciantes.

Trotsky escribió también acerca del comunismo de guerra como factor previo a la NEP, a la que respaldaba aceptando sus términos de "paso atrás" en la vía al comunismo que le endilgaron los críticos a Lenin, incluido Preobrajensky (TROTSKY, 1922).

A la muerte de Lenin en 1924 y tras el ascenso de Stalin, se subvirtió esta práctica que permitía tener elementos flexibles de la ley del valor actuando en las relaciones de producción básicas en la transición socialista -comercio entre campesinos o poblaciones sin mediación del Estado- y se pasó a una economía de tipo centralizado bajo el signo de los planes quinquenales. Durante el mandato de Stalin la URSS tuvo un alto índice de industrialización y desarrollo científico-técnico, a expensas de un nulo o escaso desarrollo teórico de la economía política debido al control ideológico y el deterioro del norte socialista en los términos argumentados por Marx y Lenin. Tras la muerte de Stalin en 1953, Nikita Jrushchov, retorna bajo el signo del cálculo económico ${ }^{9}$ a una economía planificada y centralizada, pero permisiva en térmi-

8 "Algunos de nuestros economistas no pueden admitir por principio que haya en nuestra economía no uno solo sino dos reguladores en acción [...] Temen en los hechos que la economía política no estudia sino un tipo históricamente transitorio de relaciones de producción y que su transformación en otra ciencia es absolutamente inevitable después de la revolución [...]" (PREOBRAJENSKY, 1968, p. 68).

9 Tener en cuenta que el llamado cálculo económico, no sólo tuvo desarrollo en el ámbito socialista, sino que gozó de una candente polémica en intelectuales como Von Mises, Vilfredo Pareto, Karl Polanyi, von Hayek, Oscar Lange entre otros. El tema central más allá de las tendencias era cómo hacer eficiente la asignación de los recursos y allí radicaba el carácter central del Estado en la perspectiva comunista aunque con ciertas libertades de las relaciones económicas entre las empresas estatales. 
nos de intercambio y comercio entre empresas estatales. Tal giro aseguraba el retorno hacia los principios de la NEP y por ende, como lo infirió el Che Guevara en los Cuadernos de Praga, se avistaba un giro paulatino hacia las formas capitalistas. Se hace clave recabar el control ideológico de los intelectuales dentro de la URSS. Asimismo, es importante en el marco del análisis aquí propuesto señalar que así como el checo Jindrich Zelený o los polacos Rudolf Bahro y Oscar Lange, otros intelectuales capaces de deslindarse de las directrices de pensamiento único, se gestaron en la periferia de la Unión Soviética.

Así el debate sobre el socialismo en el terreno teórico-práctico también se desdobla en: a) el gestado durante la formación y consolidación de la Unión Soviética por parte de los intelectuales que pensaban y elaboraban la política económica a partir de la ideología comunista. Éstos, reconocidos como bolcheviques, ya sea por legítima procedencia o conveniencia (HAUPT, 1972) y b) el que surge como crítica al socialismo a-científico de la nomenclatura y formado en la periferia de la URSS. Estos dos problemas serían un insumo para la Revolución cubana.

Hay que detenerse un momento en el Consejo de Ayuda Mutua Económica (CAME), órgano articulador del socialismo internacional, ya que éste expresa la práctica de la organización socialista internacional que tiene como meta la construcción del comunismo. El CAME vio la luz en enero de 1949 y fue un espacio de tensiones en donde lo socialista no era una luna de miel entre internacionalistas proletarios y, sin embargo, rindió sus frutos.

Castro (1990) interpreta al CAME como un bloque basado en intenciones políticas e ideológicas estratégicas de la URSS más que como un mecanismo internacional de planificación de las economías socialistas vinculadas a un programa de industrialización acelerado, basado en la sustitución de importaciones y en el modelo de acumulación socialista (CASTRO, 1990, p. 395).

Así todo país que pasara a integrarse al CAME debía efectuar una homologación en el marco de la división socialista internacional del trabajo. Podría decirse que el CAME fue la forma ampliada de la planificación y del cálculo económico. Su enfoque tuvo en cuenta no sólo las ventajas comparativas sino que intentó dar 
tareas a cada país para establecer una cadena productiva internacional. En el caso cubano, además de la caña de azúcar, la Isla se iba especializando en la fabricación de componentes para sistemas. Arrojas (2012) dice que:

[...] el ICID [Instituto Central de Investigaciones Digitales] fue de los primeros entre los países socialistas en desarrollar la electrónica, [...] Las computadoras importadas eran entonces caras y difíciles de adquirir por el bloqueo. A las CID-201B se les incorporaron periféricos provenientes de países socialistas europeos. Después se hizo la CID-300, un equipo que ya era parte del sistema unificado de computación de los países socialistas, al que nos incorporamos. Más tarde empezamos a desarrollar videoterminales y teclados para exportar a la URSS y otras naciones del CAME (ARROJAS, 2012, p. 21-48).

A pesar de haber formado desde mitad de los 80's una estrategia de integración de cara a la industrialización (1985-2000) denominada "Programa científico-tecnológico" y reformulada para el periodo 1991-2005 bajo el nombre de "Concepto colectiVo", los intentos de mantener vínculos de tipo económico mediante el CAME en el marco de la XLV Sesión del Concejo en enero de 1990, fueron infructuosos. Los asistentes a dicho evento ya no ostentaban adscripción al comunismo y rechazaban negociar bajo los términos de una ya desarticulada URSS, que en torno a la Perestroika (reestructuración) y a la Glásnot (apertura) aún se problematizaba el rumbo soviético en términos de una depuración del socialismo de sus elementos negativos, como se puede apreciar en la compilación llamada Perestroika (1989). ${ }^{10}$ Pese a ello, hubo distintas voluntades de los países miembros por continuar

\footnotetext{
10 En dicha publicación, varios autores se refieren al proceso de reestructuración. En sus textos, se puede apreciar que no pasaba por la mente de ellos, ni el giro hacia el capitalismo de manera tácita, ni la desintegración de la URSS Por ejemplo, Abalkin trata a la rectificación sobre el rumbo marcado por Lenin; Auzan aborda la autogestión como necesidad dentro del socialismo; Stepanov escribe sobre la eficiencia económica y la justicia social en el marco del igualitarismo, asunto que fue y es de similar centralidad en Cuba.
} 
con un CAME reformulado y que se viera en el espejo de las relaciones económicas de la Comunidad Económica Europea. ${ }^{11}$

En tal sentido, pese al signo ideológico, político y estratégico que obligaba a la URSS a formar una periferia, también existió un esmero porque tales relaciones de dependencia tendieran a subsanarse en el marco de una división socialista internacional del trabajo. Para este u otro objetivo era necesaria la articulación de las transiciones periféricas a la URSS y ello es una clave para entender en términos prácticos la recepción de la transición en Cuba. Recuérdense las preocupaciones de Lenin y Preobrajensky respecto a la ley del valor complejizadas en el contexto de un mercado socialista internacional y basada en el trueque y el rublo convertible como moneda endógena del CAME.

\section{IDEAS SOCIALISTAS CUBANAS ENTRE SIGLOS}

Una genealogía ininterrumpida de pensadores de la identidad, la soberanía, el anti-anexionismo, el anti-monocultivo y la independencia conectó al siglo XIX con el XX, tejiendo la historia de la formación de las ideas cubanas dispuestas al diálogo con el socialismo internacional de la segunda mitad del siglo XX. Se puede apreciar como actividades de vida de los pensadores la participación en las guerras de liberación, la formación de partidos y organizaciones, el periodismo, la historia, la economía, la literatura, la etnología, la antropología, la pedagogía, la ingeniería agrícola entre otras. Tuvieron una lectura crítica de Marx y Engels, hecho que exhibe una primera recepción de las ideas socialistas europeas reflejadas en algunos estudios de estos cubanos. ${ }^{12}$ Dichas ideas

11 "La reunión de Sofía se inició con un llamado del primer ministro de Bulgaria, George Atanasov, a renovar 'todo el aparato' del organismo y evitar 'su total destrucción'. La patética disyuntiva renovación o muerte' contó con la aprobación de la Unión Soviética, Rumania, Bulgaria, Checoslovaquia, Hungría, Polonia y la RDA. Sólo Cuba, Mongolia y Viet Nam manifestaron su desacuerdo." (CASTRO, 1990, p. 403).

12 Para más detalles y pensadores que se dejan fuera, revisar las obras de Molina (2007), Heinrich (1978), Le Riverend (1965), Jeifets y Jeifets (2016-18) referenciados en la bibliografía. 
nutren esta inflexión entre siglos como receptores de la teoría socialista, emanada de los bolcheviques y sus continuadores.

José Martí (1853-1895), quien viene a ser la piedra angular del pensamiento cubano de la Revolución junto al Marxismoleninismo, efectuaba sus análisis acerca de la realidad económica a su manera y estaba al tanto de la teórica y la práctica de Karl Marx. Esto se aprecia en sus artículos de prensa y en sus varias reflexiones acerca del movimiento obrero de Estados Unidos y la calidad propia de la América que compartía la historia común del coloniaje hispano-lusitano. ${ }^{13}$ En este sentido consideraba al marxismo y al comunismo como formas dispuestas para una sociedad sobre todo de tipo industrial y europea.

Carlos Baliño (1848-1879) actuó como bisagra entre Martí, con quien fundó el Partido Revolucionario cubano en 1892, y Julio Antonio Mella (1903-1929) contacto fundamental con la Komintern y motivo de varias polémicas por su expulsión del PCC. Baliño fue influenciado por la Revolución rusa y particularmente por la Reforma Universitaria de Córdoba de 1918, siendo a su vez el fundador del Partido Comunista en 1925. Baliño había constituido el Partido obrero Socialista en 1905 y es considerado el primer difusor de las ideas de Marx, -aunque Carlos Rafael Rodríguez consideraba a Jacinto Torras de la Luz (1909-1963) como el fundador de la escuela económica Marxista Leninista en Cuba- estudiándolo en Estados Unidos mientras trabajaba en una zona donde eran fuertes el lasallismo, el anarquismo y el reformismo. Además, seguía de cerca la Revolución Rusa, siendo pionero en las lecturas de Lenin en la Isla.

José Comañonga Mena (1878-1920), por su parte, vislumbraba el progreso social en Cuba pero sin revolución, por un camino a su decir, "evolutivo". Simpatizó con la Revolución rusa y por ende con

13 Martí (1875) reflexiona acerca de la implantación en México de medidas que habían funcionado en Francia. También en el diario La Nación de Buenos Aires del 29 de marzo de 1883, a quince días de la muerte de Marx, escribe: "Karl Marx ha muerto. Como se puso del lado de los débiles, merece honor. [...] Karl Marx estudió los modos de asentar al mundo sobre las nuevas bases, y despertó a los dormidos, y les enseño el modo de echar a tierra los puntales rotos [...]" (MARTÍ, 1883). 
la socialización de la tierra como forma de promover más propietarios privados. En 1925 escribió Sovietismo y solidarismo, donde muestra el impacto de la Revolución de Octubre en la burguesía y pequeño-burguesía cubana. Al respecto refiere Molina (1999):

En el folleto pretende divulgar los principios y el pensamiento de la Asociación Nacional Azucarera fundada en 1923 y que constituye un manifiesto pequeño-burgués, promotor de la conciliación entre obreros y capitalistas de la industria azucarera: que lograran unas bases de inteligencia entre hacendados y colonos, para prevenir todo conflicto entre patronos, operarios y obreros. (MOLINA, 1999, p. 79).

Su obra más relevante, La nueva economía agraria en Cuba, de 1929 señala la urgencia de acabar con el monocultivo.

Antonio Guiteras Holmes (1906-1935) tuvo una visión preclara marxista que entiende la instauración de un socialismo de Estado como tarea compleja, sobre todo cuando se trata de una transición del coloniaje hacia la sociedad socialista. Finalmente, Carlos Rafael Rodríguez (1913-1997) fue uno de los cuadros políticos y teórico del aparato económico revolucionario desde 1959. Militó desde 1936 en el Partido Comunista Cubano. De formación marxista aplicada al contexto no sólo cubano sino latinoamericano, llegó a ser, al lado de Celso Furtado, uno de los primeros observadores en la apreciación de la dicotomía entre crecimiento y desarrollo económico. Fue el responsable de la dirección de la economía cubana por varios años y formó parte del grupo de revolucionarios que pensó la transición socialista.

Esta breve semblanza, que omite algunas referencias y pensadores, constata la forma en que se gestaba el discurso socialista desde la singularidad del proceso histórico cubano entre siglos, desde su independencia de España en 1898 hasta la ocupación estadounidense que apuntalaba su injerencia con la Enmienda Platt de 1901. La aproximación casi en tiempo real a los fenómenos europeos y la capacidad de hacer estudios para la realidad isleña desde una perspectiva sociológica, económica e histórica, cuando no de facto inspiradas en el análisis marxista o las experiencias bolcheviques, dan cuenta de una temprana recepción 
del socialismo europeo y eslavo, que luego aterrizaría de manera práctica en la incorporación de los referentes de transición socialista soviéticos. También el humanismo y universalismo de Martí se articula a la forma sui generis de una Cuba Socialista.

\section{EL DEBATE EN CUBA}

El sentido socialista de la Revolución era una certeza en la cabeza de Ernesto Guevara, Fidel ${ }^{14}$ y Raúl Castro y quizá de Carlos Rafael Rodríguez. El capitalismo no era una opción para su dirigencia y la relación teoría - realidad, entran de inmediato en diálogo al iniciar la regencia del Estado. Como señala Martínez (2003): ${ }^{15}$

El debate entre los revolucionarios era --y es siempre-- un ejercicio indispensable para la vida del socialismo, porque la nueva sociedad hay que crearla, exige invenciones, intuiciones, y una combinación rara de rigor y audacia, de principios y herejía, de fidelidad y ejercicio del criterio propio (MARTíNEZ, 2003).

La recepción de la literatura soviética tiene matices que es necesario señalar: i) Si se habló desde el año 1959 de un proceso de alfabetización, hay que tener presente que el acceso a tal literatura, entabla un reto con dos aristas: por un lado, un aprendizaje funcional de la lectura; por otro, la capacidad de discernir la narrativa de los autores rusos y entender qué de ella puede devenir en una impostura y qué podía ser afín entre la cultura caribeña y la eslava en el contexto de la construcción del socialismo desde la economía, la política, el arte, el teatro, la danza, el deporte, la ciencia, la novela etc. ii) La forma de aproximarse al marxismo-leninismo luego de Playa Girón no fue ni lineal ni simple; por el contrario, se vio marcada por tensiones entre partidarios sectarios del PC, las ideas acuñadas en el Movimiento 26 de Julio, -- heredero de las demandas del Programa del Moncada - (M26-J) y demás grupos que pensaban el nuevo rumbo en Cuba. iii) A nivel de la cultura,

14 Gambina (2016).

15 Esta referencia al autor se encuentra en un sitio electrónico. Por ello, no indicamos las páginas de esta citación o de las demás retiradas del mismo texto. 
la literatura y las artes, la Isla fue resistente a la ideologización y la imposición del "realismo socialista" como receta para explicar y apologizar al socialismo naciente en Cuba o el campo socialista, aunque fuera de la misma existe literatura que controvierte esta suerte de purismo. ${ }^{16}$ iv) Bajo las anteriores salvedades, hubo un interés y recepción de la Revolución bolchevique, el comunismo y el marxismo que emanaba de éstos. Martínez indica la búsqueda de las obras de Lenin, Trotsky, Gramsci, Lunacharski así como artistas de la talla de Maiakovsky, Tatlin, Brecht y Gorki. El cine y los congresos de literatura soviética fueron acogidos por el público cubano (MARTÍNEZ, 2010, p. 59). v) Cuando se decidió el rumbo socialista en la Isla, vino también el problema de la formación en la academia, incluyendo la enseñanza de materialismo dialectico y de materialismo histórico a partir del manual de Konstantinov. Las Escuelas del Partido continuaron con líneas más cerradas sobre la línea soviética, mientras las universidades y sus departamentos, que debían impartir los "materialismos" en todas las áreas, nutrieron con varios autores sus cátedras: Lenin, Svidierski, Rosenthal, Garaudy y posteriormente, Weber, Lévi-Strauss, Marcuse, Lukács, Sartre, Korsch y más tarde Althusser, entre otros. vi) Existe una relación entre los intelectuales cubanos, las actividades académicas, las actividades militares, la acción práctica de la cotidianidad y la promoción cultural mediante revistas y autores. Medios como El Caimán Barbudo, Juventud Rebelde, Pensamiento Crítico, el Libro Amarillo, la propia Casa de las Américas, el Libro Verde, Teoría y Práctica - de línea teórica de tipo marxista soviético- así como otras fuentes emanadas de los Ministerios sumaban complejidad a la ruta socialista cubana. Era inevitable plantear una ruptura con la literatura cerradamente marxista ortodoxa y pasar, hacia el estudio de los bolcheviques pero acercándolos a la realidad del Caribe

16 Franco (2003). El texto aborda el trabajo ingente de Casa de las Américas, como proyecto editorial de raigambre no imperial. Esto a contrapelo de la revista Mundo Nuevo, patrocinada por la CIA. En el capítulo 3, "Territorios Liberados", desarrolla mejor cómo se gestó la tensión y cierta cortina que blindara ideológicamente a la Revolución Cubana. Allí, el ítem "Dentro/fuera, fuera/dentro", desarrolla puntualmente esta idea de límite entre aquellos autores internacionales que estaban con o contra la Revolución. 
(MARTÍNEZ, 2010, p. 94). Esto es de suma importancia pues leerlos significaba verse proyectados en aquellas tareas que aquejan en el periodo de transición a la sociedad cubana. Cabe anotar que en este sucinto resumen se omiten momentos de tensión interna devenida de las múltiples afiliaciones e ideas de futuro ideológico-político gestadas desde antes de 1959 y que se articularon a la construcción del comunismo, mediante el socialismo, desde abril de 1961, tras la victoria cubana en Playa Girón.

En esta época, el Che Guevara buscaba un experto en planificación y por recomendación de Paul Sweezy y Leo Huberman, contactó a Charles Bettelheim, quien se había fogueado en el acompañamiento a los gobiernos de India y Egipto, y que arribó a Cuba en calidad de asesor en agosto de 1960.17 También se recibió la perspectiva de la CEPAL en el acompañamiento a la Junta Central de Planificación (JUCEPLAN) por parte del economista mexicano Juan Noyola. Esta perspectiva progresista fue eclipsada por la planificación socialista.A la presencia de Bettelheim se sumó la de Jacques Chonchol, agrónomo chileno que provenía de la FAO y la de René Dumont agrónomo marxista de reconocida trayectoria. En 1959 a su paso por Cuba, en el contexto de una gira por países subdesarrollados, el polaco Michal Kalecki dejó unas Proyecciones para el periodo 1961-1965, que sirvieron de base para el "Modelo Esquemático del Plan 1962-1965 para la Economía Cubana", elaborado por Bettelheim.

Orlando Borrero, como colaborador directo de Guevara, afirma en una entrevista que desde 1960-1961 se abre un círculo de estudios sobre El Capital donde participan Mansilla, profesor de El Capital en la Universidad de Lomonosov -con quien Guevara tenía una polémica ante las acciones de la URSS- Fidel Castro, Carlos Rafael Rodríguez y Regino Botti - economista formado en Harvard (KOHAN, 2003). Hubo además un segundo seminario en el

17 Díaz y Bettelheim (2011). La elección e impacto de Bettelheim se deben a: la concepción de la planificación económica que él defendía y defendió hasta su muerte en el 2006, de inspiración tercermundista, apuntaba a tres objetivos: la industrialización, la modernización de la agricultura y la diversificación de la economía, con el fin de asegurar la independencia económica de los países recientemente descolonizados. 
Ministerio de Industrias donde se sumaron otros cubanos dirigentes de ministerios y el embajador, en calidad de observador ante el CAME, Francisco García Vals. El seminario duró un año en el cual, según Borrero, se estudió la totalidad de El Capital. A partir de tal círculo los cubanos leyeron a Trotsky y recibieron la visión de Mansilla acerca de Preobrajensky -revisionista a los ojos de éste- e indaga en La nueva economía, que los puso frente al debate acerca de la NEP de quien Guevara era un crítico. Ernest Mandel, por su parte, conversó en varias oportunidades con Guevara y Borrero, llevándoles el Tratado de economía marxista. Guevara leía a Oscar Lange en sus aspectos econométricos y creía poder aplicarlos al caso cubano pero sin cálculo económico; es decir, sin relaciones monetarias entre "empresas consolidadas". De hecho, Martínez (2003) señala que:

En 1962 había comenzado en la URSS un debate a partir del artículo de E. Liberman "Plan, beneficio, primas", alrededor del criterio de rentabilidad, el alcance del plan central y la estimulación a las empresas a buscar más eficiencia mediante más autonomía, el interés material y una política de incentivos a los trabajadores. Aquel debate fue un paso hacia la reforma económica soviética en 1965, y reformas análogas, aunque con sus especificidades, que sucedieron en otros países de Europa oriental. Como es natural, esas ideas iban llegando a nuestro país. (MARTíNEZ, 2003).

Al decir de Borrero, a Guevara lo marcó la obra utópica del estadounidense Edward Bellamy titulada El año 2000. Bellamy retrata una sociedad socialista en Estados Unidos donde las relaciones monetario-mercantiles serían inexistentes; tal cual lo imaginaba Guevara. Sería sólo una anécdota si el objetivo de Guevara no hubiese sido la expresión y el propósito de este sentido en el Sistema Presupuestario de Financiamiento (SPF).

Mandel, como se adelantó, estuvo en Cuba entre 1963-1964 y no era partidario de la NEP; hecho que lo acercaba a Guevara. En estos años el Che Guevara llevó adelante el debate con Bettelheim respecto al cálculo económico y la planificación socialista mediante contacto epistolar así como a través de algunas publicaciones 
como Nuestra Industria Revista de Economía, o Cuba Socialista. El tema que primaba en la crítica guevariana al cálculo económico era la flexibilidad de los agentes del mercado los cuales daban aún mucha libertad a la circulación monetaria y por ende a la compra y venta de mercancías tanto en particulares como entre empresas y éstas, que a su parecer, debían ser un ejemplo en la gestión. Para Guevara la urgencia de llevar un proyecto radical, transformador de la conciencia, exigía la elevación de ésta mediante una supresión o reducción de los estímulos materiales y un fomento a los morales, sin descalificar a los primeros. Bettelheim estimaba que era necesario desarrollar las fuerzas productivas y las relaciones de producción bajo la siguiente premisa: creando la mayor cantidad de satisfactores de las necesidades, modo en que los hombres podrían adquirir o formar conciencia. Según Borrero en este aspecto, Guevara se afincaba en los Manuscritos económicos y filosóficos de 1844 que retratan la carga filosófica y antropológica del Marx joven y tienen como tema central al trabajo y la enajenación. ${ }^{18}$ En el Ministerio de Industrias hacia 1964, se desarrollaron círculos de estudio de los cuales quedaron algunos registros en los Apuntes críticos a la economía política. Los temas iban desde análisis de factores internos del Ministerio y los estímulos morales, hasta el nivel de injerencia que el partido tenía o debía tener sobre la dirigencia empresarial.

El Sistema Presupuestario de Financiamiento constituye la síntesis entre planificación soviética, los ajustes del mismo a la realidad cubana y cimentados en la convicción guevariana de la construcción simultánea de conciencia y base material socialista, como única forma de lograr allanar la enajenación, desde la transición socialista. Decía Guevara que: "El socialismo económico sin moral comunista no me interesa. [...] si el comunismo no se preocupa del hecho de conciencia, se convierte en un método de

18 En la explicación que hace Guevara (1970) acerca del Sistema Presupuestario de Financiamiento así como una comparación con el Cálculo económico, evoca los manuscritos, dando como central el complemento entre el Marx joven filósofo y humanista, con el Marx riguroso y materialista de El Capital. Con ello concilia la necesidad del socialismo, no sólo como práctica económica sino moral. 
distribución pero no será nunca una moral revolucionaria" (citado en TABLADA 1987 , p. 38). ${ }^{19}$

Pero el arribo de Cuba a la economía y las relaciones con el CAME era inevitable. Siendo el cálculo económico el sistema dominante en la URSS, Cuba entabló una forma flexible respecto a los agentes mercantiles análoga con el Sistema de Dirección y Planificación de la Economía (SDPE). Pero esto sucede hasta los años 70's. En el lapso 1966-1972, a la luz de investigadores como Vilariño y Domenech (1986, p. 89), se aprecia una carencia de planificación pero con fuerte centralización de funciones - esta relación dirigencia política vs dirigencia empresarial criticada por Guevara - que ante una radicalización del estatismo, provocó un déficit de suministro de bienes y servicios y también reafirmó la negligencia en la entrega de materiales o la no puesta en funcionamiento de tecnología suministrada por el ala soviética; carcomida por el óxido en los puertos a falta de gestión (MESA-LAGO, 2002). El burocratismo - que también se hace presente en el capitalismo - creció y concentró poder en detrimento del socialismo mismo.

De esta manera, entre 1972-76 y 1985, Cuba bajo el SDPE encontró cierto equilibrio en su gestión económica, apalancada en los precios preferenciales sobre el azúcar. Es precisamente este momento - año 1985- en el cual se avista por parte de la dirigencia cubana un decaimiento del sector socialista internacional; claro está, sin tener la certeza de su debacle cuatro años más tarde. En la XLV Sesión del CAME, conocida como "El acuerdo de Sofía", ya se aprecian las preocupaciones que se iban tejiendo en torno a la reforma a los precios preferenciales a Cuba por la caña de azúcar. Al respecto Castro (1999) observa que:

Cuba recibe un precio especial de casi el doble del internacional por el azúcar que envía a Moscú (4.3 millones de toneladas en 1988). De prevalecer la propuesta soviética representaría un duro golpe para la economía cubana. Lo mismo ocurriría con Vietnam, y Mongolia, países que se oponen a la restructuración del CAME. Carlos Rafael Rodríguez, delegado

19 Tablada (1987) lo toma de una entrevista en Argelia efectuada por Jean Daniel titulada "La profecía del Che". Texto publicado en Buenos Aires en 1964. 
cubano a la reunión del Consejo, no ocultó su preocupación ante las reformas que se avecinan. No sólo por el retiro o la disminución de los subsidios comerciales soviéticos, sino por la posibilidad de que la URSS y los países de Europa del Este adquieran alimentos de Occidente, con lo cual los productos cubanos tendrían enormes dificultades para colocarse. Las negociaciones a puerta cerrada seguramente incluyeron amplias deliberaciones y negociaciones acerca del "caso especial" de Cuba (CASTRO, 1990, p. 403).

La "Rectificación de errores y tendencias negativas" como periodo de balance dado a mitad de los 80's entendió que el SDPE, análogo del cálculo económico, pervertía la moral y la conciencia revolucionaria. Por esta razón las "tendencias negativas" se enfocaron hacia una vuelta al estatismo y a las prácticas del SPF de inspiración guevariana. El advenimiento del Periodo Especial en Tiempos de Paz obligó, en contra de la anterior apreciación de la Rectificación, a insertar más agentes mercantiles para soportar los embates del bloqueo y el aislamiento total de la Isla, ya con socios comunistas inexistentes. De tal forma, el debate en Cuba vuelve a plantearse ya no bajo los signos utópicos de los 60's ni bajo el fervor de los jóvenes revolucionarios que señala Martínez (2010). En ese momento y ante el acercamiento diplomático con ciertos avances en la mesa cubano-estadounidense -que no impactan los temas centrales de la agenda, la reflexión sobre el socialismo en Cuba, -qué significa, cómo se hace vigente, en el marco de la actualización del modelo económico- vuelve a estar presente con fuerza e inevitablemente plantea, la cuestión de la transición como enfoque de la tendencia de tipo marxista y filo-soviética de su intelectualidad.

\section{DE TRANSICIÓN AL COMUNISMO HACIA EL NO CAPITALISMO}

Al declararse Cuba socialista a inicios de los 60's, por inercia se comprometió con la construcción del comunismo y al día de hoy cuenta con el Partido Comunista como su órgano político más representativo. Planteárselo a la luz del marxismo-leninismo 
significó el reconocimiento de la literatura soviética que modelaba la transición; viviendo Cuba los síntomas dialécticos que precedieron la transición en la URSS. Al ponerse como reto el arribo al comunismo, aunque se tardaran toda una vida en el socialismo, como señaló el Che Guevara, la transición, como tensión y conflicto entre la nueva y la vieja sociedad, -vieja pero no muerta, ni senil- no sólo se daba desde un capitalismo subdesarrollado hacia el comunismo, sino también bajo el riesgo latente de ir en sentido inverso y con el arribo aplazado.

El periodo de transición en el socialismo, desde el marxismo, es una tensión constante entre teoría y realidad, entre el plan y la ejecución. En tal sentido, frente a lo que podían decir los manuales provistos de más incertidumbre que ideas concretas, Cuba, ante los embates que dieron paso al Periodo Especial, cambió su socialismo de medio para comprender al comunismo a un fin en sí. ${ }^{20}$ Esto implica el fin de la transición, tal cual la enuncia la teoría marxista. Entonces, ¿Cuál será ahora la transición en la Isla? ¿Cómo entender la experiencia socialista cubana actual, a partir de las pautas de la literatura marxista-leninista? Quizás se está ante esa chispa de herejía que se hace necesaria para conjurar la inmovilidad que tiende a proponer la lectura ortodoxa del manual.

El asunto de la polémica con la ley del valor como elemento determinante en la nueva sociedad se abandonó y en parte también la formación de conciencia frente al consumo atizando

20 Preámbulo de la Constitución Política de Cuba de 1976: (...edificar la sociedad comunista...) y 2002 Preámbulo: (... continúa con el objetivo final de edificar la sociedad comunista.) Documentos emitidos desde el PCC, antes y durante el Periodo Especial: En el Primer Congreso de 1975 su aparte Tesis y resoluciones sobre el la plataforma programática: (... el logro de los objetivos finales de todo trabajador: la construcción del socialismo y el comunismo) A contrapelo con los Estatutos de 1998 (...la construcción del socialismo, sobre la base de los principios revolucionarios [...] El partido comunista, cuyo objetivo esencial es la construcción del socialismo) Además en los Lineamientos de Política Económica y Social del partido y la Revolución, (Consejo de Estado VI Congreso del Partido Comunista de Cuba. La Habana, 2011), así como en Conceptualización del modelo económico y social cubano de desarrollo socialista. Plan nacional de desarrollo económico y social hasta 2030: propuesta de visión de la Nación, ejes y sectores estratégicos. (Séptimo Congreso del Partido. La Habana. 2016) el norte comunista no está presente. Todo gira en torno al desarrollo socialista, la democracia socialista, la actualización del modelo socialista, propiedad socialista, Estado socialista, etc. 
el individualismo. Además, la propia dificultad comercial a causa del bloqueo le provee poco margen de acumulación a Cuba, con lo cual la acumulación socialista - al menos elemento central en la teoría económica de Preobrajensky (1968) - está suspendida. Al quedar Cuba sola, le fue imposible desarrollar intercambios no desiguales y debió alinear su comercio internacional a las leyes capitalistas triunfantes en 1989. Por ende, y sin censurar el inevitable rumbo de la Isla y a la vez reconociendo el mantenimiento en la inversión social pese a la crisis del Periodo Especial, el socialismo en Cuba inició un movimiento pendular entre un "no capitalismo y un no comunismo". Una NEP a lo cubano. En tal orden de ideas, en Cuba aún no se resuelve si se gestó o se gesta el Hombre Nuevo - nueva humanidad- pero lo claro es que al redefinir las metas, volverse fines en sí mismos, y teniendo presentes los demás elementos señalados, se acerca peligrosamente a los modos de la vieja y latente sociedad capitalista dominante por más de seis siglos, las cual penetró a las nuevas - y no tan nuevasgeneraciones de cubanos.

Es evidente que Cuba en 58 años de Revolución ha vivido los síntomas de la transición como signo de su norte ideológico a contrapelo con el hegemónico, y no se puede hablar de una tendencia estacional definitiva. Por lo mismo es prudente referir que se dirige hacia formas al menos no capitalistas, pero también, no comunistas. El socialismo cubano bien puede ser una tendencia capaz de reacomodarse a las circunstancias tal cual lo hace el capitalismo. Lo clave es que hasta ahora, aunque cada vez con más dificultades en su mantenimiento, el modelo cubano ha solventado una política social y un desarrollo en ciencia y tecnología producto de su concepción socialista de Estado y sociedad.

\section{NOTA DE CIERRE}

La recepción de los elementos problemáticos de la transición en Cuba, guardó cierta concordancia con los exhibidos en la experiencia soviética, pues las dos eran hijas de la perspectiva marxista, y a su vez se matizó de los agentes endémicos. La recepción de la vena bolchevique se apalancó en la base intelectual cubana 
gestada significativamente a finales del siglo XIX y principios del $\mathrm{XX}$, con un agente dinámico, original y nativo: el pensamiento Martiano. La influencia soviética se explica por dos razones: i) la construcción teórica que subyacía en ella anclada al marxismo afín con un sector del pensamiento cubano de entre siglos y ii) la ineludible adscripción en el marco de la Guerra Fría a la construcción del comunismo vía socialismo, expresada en el CAME, que articulaba las transiciones nacionales a la gran transición socialista internacional. Fue expresión de la influencia soviética, la vida académica, la formación de los programas de estudio, los autores compartidos mediante las publicaciones que en la Isla, expresaban tendencias teóricas. Y la recepción del debate en Cuba a partir de la tendencia guevariana radical -que lideró la iniciativa de su estudio - frente al uso de mediadores monetarios entre las empresas consolidadas, altamente centralizador y configurado a partir de una fórmula: "moral más eficiencia económica" ha prolongado el debate sobre el socialismo cubano. Al encontrarse Cuba sola en la construcción - y defensa - del socialismo, se aprecia hoy, como no es capitalista así como tampoco comunista. La influencia soviética en Cuba sigue latente y se expresa en los diversos grupos que en el seno de la izquierda, hoy hacen la política, la ideología y la economía cubanas. De ello deviene una polémica latente respecto a si Cuba vive aún los embates de la transición, al menos para consolidar su socialismo, y si éstos se contemplan dentro del margen de la dialéctica histórico materialista marxiana.

\section{REFERENCIAS}

ARROJAS, F. Caminar aterrizando las cosas: habla la ciencia cubana. La Habana: Editorial científico-técnica, 2012.

CASTRO, P. F. El CAME. Economía y política. Comercio Exterior, [s.l.], v. 5, n. 40, p. $395-405.1990$.

DÍAZ, S.; BETTELHEIM, C. En la revolución cubana: economía y socialismo. La Habana: Ruth Casa Editorial, 2011.

FRANCO, J. Decadencia y caída de la ciudad letrada: la literatura latinoamericana durante la Guerra Fría. España: Editorial Debate, 2003. 
GAMBINA, J. Fidel Castro y su aporte a la transición. El Blog de Julio C. Gambina, 26 nov. 2016. Disponible en: <http://juliogambina.blogspot. com.co/2016/11/fidel-castro-y-su-aporte-la-transicion.html>. Acceso en: 6 ago. 2017.

GUEVARA, E. La planificación socialista y su significado: escritos económicos varios. Bogotá: Círculo Rojo editores, 1970.

HAUPT, M. J. G. Los Bolcheviques. México: Editorial Era, 1972.

HEINRICH, F. Historia económica de Cuba 1. La Habana: Editorial de Ciencias Sociales, 1978.

HOBSBAWM, E. Cómo cambiar el mundo. España: Editorial Crítica, 2011.

JEIFETS Víctor y JEIFETS Lazar. El encuentro de la izquierda cubana con la Revolución Rusa: el Partido Comunista y la Comintern. Artículo resultado de una investigación financiada por la Fundación Científica Rusa de Humanidades (RGNF) (proyecto núm. 16-01-00138). P. 81 - 100. 2016-2018

KOHAN, N. Che Guevara lector de El Capital: Entrevista a Orlando Borrero. Rebelión, 02 jul. 2003. Disponible en: <http://www.rebelion.org/noticia. php?id=51>. Acceso en: 19 out. 2017.

LE RIVEREND, J. Historia económica de Cuba. La Habana: Editorial Universitaria, 1965.

LENIN, V. Teoría economía y economía política en la construcción del socialismo. La Habana: Editorial Roca, 1974.

MARTÍ, J. Honores a Karl Marx, que ha muerto. La Nación de Buenos Aires, [s.l.], 29 mar. 1883.

La polémica económica. Revista Universal, México, 23 sep. 1875.

MARTÍNEZ, F. El Che y el gran debate sobre la economía en Cuba. Revista Rebelión, La Habana, jul. 2003

A viva voz. La Habana: Editorial de Ciencias Sociales, 2010.

MARX, K.; ENGELS, F. Manifiesto del partido comunista. México: Centro de estudios socialista Karl Marx, 2011.

MARX, K. Crítica al programa de Gotha. Moscú: Editorial Progreso, 1986.

MESA-LAGO, C. Buscando un modelo económico en América Latina: ¿Mercado socialista o mixto? Chile, Cuba y Costa Rica. Venezuela: Editorial Nueva Sociedad, 2002. 
MOLINA, E. Pensamiento económico de la nación cubana. La Habana: Editorial de Ciencias Sociales, 2007. . Perestroika: problemas, búsquedas y pronósticos. La economía soviética, Moscú, n. 1, p. 87 - 98, 1999. [Editorial de la agencia de prensa Nóvosti].

PREOBRAJENSKY, E. La nueva economía. 2. ed. La Habana: Instituto del libro, 1968.

SAENZ, R. Plan, mercado y democracia obrera: la dialéctica de la transición socialista. Revista Socialismo o Barbarie, [s.l.], n. 25, p. 141 -250, 2011.

SHANIN, T. El Marx tardío y la vía rusa. Madrid: Editorial Revolución, 1983.

TABLADA, C. El pensamiento económico de Ernesto Che Guevara. La Habana: Ediciones Casa de las Américas, 1987.

TROTSKY, L. Informe sobre la nueva política económica soviética y las perspectivas de la revolución mundial: presentado ante el IV Congreso de la Internacional Socialista. Moscú: [s.n.], 1922.

VILARIÑO RUIZ, A.; DOMENECH, S. El sistema de dirección y planeación de la economía en Cuba: historia, actualidad y perspectiva. La Habana: Editorial Pueblo y educación, 1986. 